\title{
Geographic Distribution of Africanized honeybees (Apis mellifera) Reflects Niche Characteristics of Ancestral African Subspecies
}

\author{
Marcos Vinícius Carneiro Vital ${ }^{1 *}$, Randall Hepburn², Sarah Radloff ${ }^{3}$ \& Stefan Fuchs ${ }^{4}$
}

${ }^{1}$ Instituto de Ciências Biológicas e da Saúde, Setor de Biodiversidade e Ecologia, Universidade Federal de Alagoas - UFAL, Maceió, AL, Brasil

${ }^{2}$ Department of Zoology and Entomology, Rhodes University, Grahamstown, South África

${ }^{3}$ Department of Statistics, Rhodes University, Grahamstown, South Africa

${ }^{4}$ Institut für Bienenkunde (Polytechnische Gesellschaft), Fachbereich Biologie der Goethe Universität am Main, Karl-von-Frisch, Oberursel, Germany

\begin{abstract}
The introduction of the Africanized honeybees (Apis mellifera scutellata) in the New World is reported as one of the most successful exotic species invasion ever known. Here, we analyzed this invasion process through niche modeling approach, comparing the performance of modeling A. m. scutellata with other African subspecies distributions, projected into the New World. We applied the Genetic Algorithm for Rule Set Production (GARP) on a dataset of the original distribution of the subspecies in Africa. Only data from A. m. scutellata and A. m. jemenitica generated projected distributions in the Americas that resemble closely the current distribution of Africanized bees. These results suggest that the current distribution of Africanized honeybees in the New World to a great extent reflects niche characteristics from the subspecies that was originally introduced, reflecting a niche conservatism process.
\end{abstract}

Key words: Niche Conservatism, Species Distribution Modeling, Species Invasion, GARP, Apis mellifera scutellata.

\section{Introduction}

The invasion of non-native species is a well-known outcome of human activities that can be traced way back in the history of mankind. The direct and indirect consequences of such introductions vary from negligible effects to the extinction of native species and public-health impacts (Lodge \& Shrader-Frechette 2003). Therefore, much effort has been spent in trying to find out how to prevent (or minimize, at least) the impact from the introduction of a species (Myers et al. 2000).

Controlling established populations of invasive species, however, often turns out to be an extremely defying task (Genovesi 2005). Thus, foreseeing non-native species' potential distribution can be highly valuable as a proactive assessment to deal with species invasions (Peterson 2003). The potential of a given species to occupy any environment can be assessed via the evaluation of niche related characteristics (usually climate and topographic related variables) from

*Send correspondence to: Marcos Vinícius Carneiro Vital Instituto de Ciências Biológicas e da Saúde,

Setor de Biodiversidade e Ecologia, Universidade Federal de Alagoas - UFAL, CEP 57072-900, Maceió, AL, Brasil

E-mail: marcosvital@gmail.com the native distribution, which can predict the suitability of the new habitat conditions (Peterson 2003).

Apis mellifera scutellata was introduced in Brazil in 1956 and during the last 50 years it has rapidly spread throughout the Americas, extending from the northern Argentina to the southern US. The spectacular success of the "Africanized" honeybees in these continents is thought to be one of the most successful biological invasions ever recorded (Schneider et al. 2004), although the occupation process itself is not finished. Also, some phenotypic and genotypic changes occurred during this introduction process, due to racial admixture with previously established European subspecies or adaptation to new environmental conditions. Given the negative economic, natural and public-health impacts that this introduction was expected to cause, several predictions of its future range have been developed (Taylor 1977; Harrison et al. 2006), although there are positive effects, such as an increase in South American honey production (Araújo 1971).

Here, a niche-modeling approach is applied in a retrospective evaluation of this invasion process, and the invasive performance of $A$. m. scutellata is compared with other 
African subspecies by modeling niches in Africa and comparing projected distributions in the New World. Special attention is given to the discussion of A.m. scutellata potential distribution, since this can be relevant to predict the africanized honey bees expansion in North America. Currently, there are several different techniques available for modeling species' distributions, each of them using specific approaches for relating known distributional data to niche variables (see Elith et al. 2006, for a comparative evaluation of various methods). Assessing the overall performance of modeling methods is not a straightforward task that could lead one to choose "the best technique", since different approaches are known to behave differently under specific conditions, such as species and/or environment idiosyncrasies (Elith et al. 2006). In this study, the Genetic Algorithm for Rule Set Production (GARP), an algorithm that has shown good predictive ability of the potential distributions of species (Stockwell \& Peterson 2002; Anderson et al. 2003) is applied. Whilst GARP performance seems to be inferior when compared with new methods (e.g., MAXENT) under the "typical" circumstance of modeling a species' distribution on its native habitat (Elith et al. 2006; also, see Stockman et al. (2006) and references therein, for a discussion over an evaluation of GARP models), its ability to predict a distribution in unsampled regions (known as transferability) (Peterson et al. 2007) make it a suitable choice for this study. GARP has been widely applied to help understand patterns of species invasions (Peterson \& Vieglais 2001; Peterson 2003; Peterson \& Robins 2003), both to predict future invasions or with the purpose of understanding past processes.

\section{Material and Methods}

Models of the potential distribution of Africanized honeybees in New World were constructed using data from seven subspecies of Apis mellifera L. in their original distribution in Africa. A data set of occurrence points built with the combined data from the Institut für Bienenkunde (Ruttner collection, Oberursel, Germany) and from the Apiculture Group at Rhodes University (Hepburn and Radloff collection, Grahamstown, South Africa) was used. The subspecies considered in this analysis were: A. m. scutellata (207 occurrence points), A. m. adansonii (99 points), A. m. capensis (33 points), A. m. intermissa (19 points), A. m. jementica (72 points), A. m. litorea (34 points) and A. m. monticola (41 points). The listed numbers of occurrences refer to spatially unique occurrence points, which means that more additional occurrences within the limits of any given cell of the environmental variables grid are ignored. We are aware that $A$. mellifera subspecies represent rather a continuous variation of characteristics than clearly discrete units (Hepburn \& Radloff 1998). However, since modeling would be impossible without establishing distinct groups (to define several "niches" at subspecific level), statistically discrete morphoclusters based on high probability values of assigning a given sample to a "subspecies", based on previous morphometric analysis (Diniz-Filho et al. 2000) were used to define experimentally discrete groups.

The africanized honey bees distribution is known to be strongly limited by climatic variables such as temperature and precipitation (Harrison et al. 2006). Thus, to perform the modeling, nine climate related environmental variables that are included in desktop GARP (an implementation of GARP algorithm) were used: digital elevation model, ground frost frequency, mean daily precipitation, solar radiation, mean, minimum and maximum annual temperature, vapor pressure and wet day frequency. GARP was run 200 times for each subspecies (2000 iterations at each run), setting the convergence limit to 0.005 and the omission error to zero. The 20 "best subset" (Anderson et al. 2003) models were then pooled together to obtain combined maps, assigning a rank expressing increasing levels of confidence in predicting occurrence in a given region.

GARP methodology is widely described in the literature (Anderson et al. 2003), but two features deserve further thought here. Both papers that originally proposed using GARP in predicting species invasions suggested that the niche should be modeled in the natural distribution of the organism and then projected into the invaded area (Peterson \& Vieglais 2001; Peterson 2003). However, when proceeding this way the models left several regions without a prediction of either presence or absence. In addition, the models provided spurious results, such as the prediction of A. $m$. intermissa occupying the north of Canada. This could result because as the modeling is restricted to a limited area (like Africa), too few "pseudo-absence points" are left, and the models get too many irrelevant variables. Thus, all models presented here were obtained by modeling the distribution in the whole world at once (though only the results on the Americas are considered), although the expression "projected distribution" was retained here for clarity.

In order to compare the subspecies projected distributions between continents, both New World and Africa were divided in a grid of $1^{\circ}$ resolution cells, and the proportion of models predicting a given subspecies in each cell was calculated. Thus, each subspecies had two vectors (one for Africa and another for America) showing the number of GARP models predicting occurrence in each cell, and these vectors were used to compute Euclidian distance matrices comparing the distribution of the seven subspecies within each continent. A Mantel test (Manly 1997) was then carried out to correlate the two matrices, under the null hypothesis that pairwise similarity between subspecies is random in respect to African and American continents. Deviations from null hypothesis were established using 5000 random permutations.

\section{Results}

Figure 1 shows in detail the combined 20 best subset models based on A. m. scutellata's distribution. High 


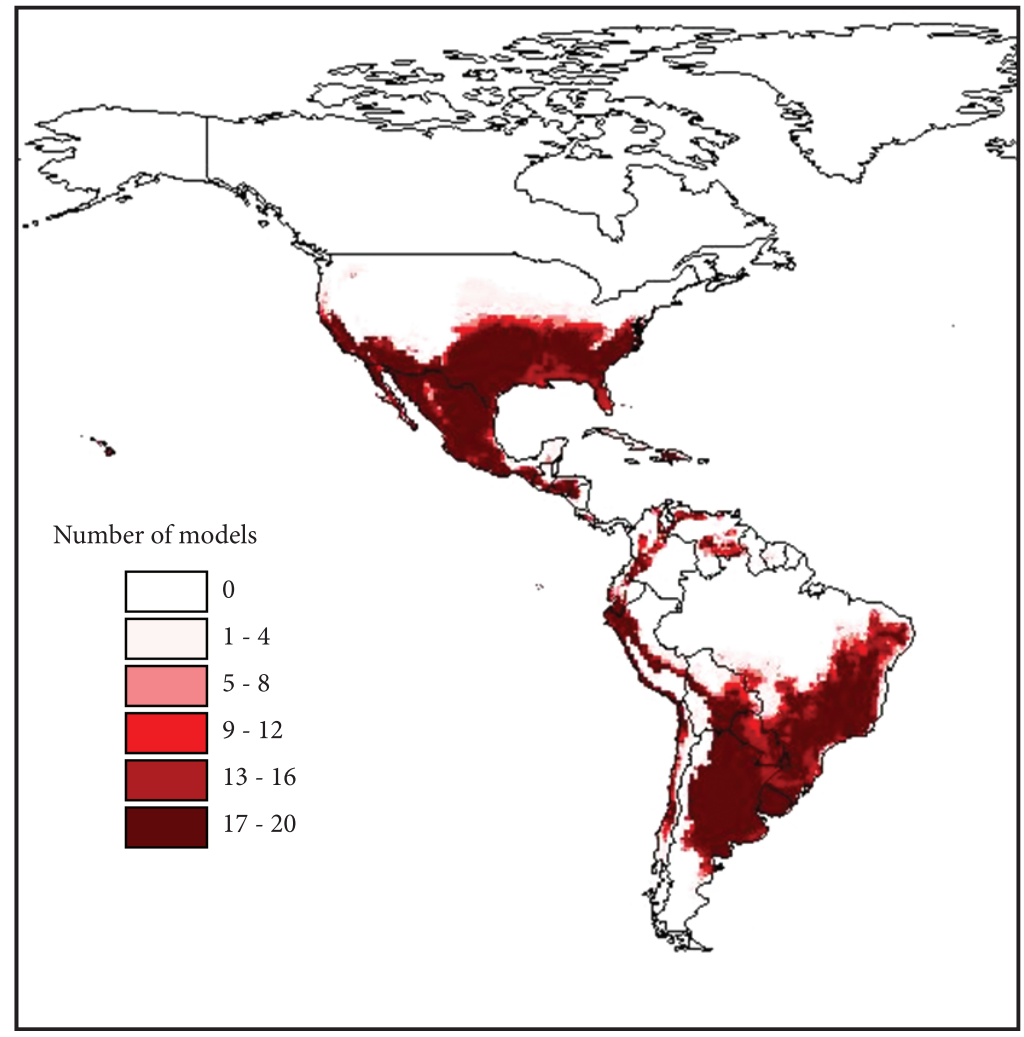

Figure 1. Projections of predictive models based on data of the original distribution of A. m. scutellata in Africa. The color scale represents the number of models predicting the occurrence in the same place.

overlap of GARP predictions, revealing strong confidence of occurrences, are found in eastern cost of South America, in Argentina east to Andes and in Mexico and southern US. Some other distinctive features in these models are the absence of occupied areas in the Amazonian region and the presence of potential areas in the eastern US (covering a large region that is not occupied today).

The projected distributions of African honeybees in the New World for all modeled subspecies are shown simultaneously in Figure 2, along with their original distribution in Africa. Every subspecies has a distinct projected distribution, but A. m. scutellata's is clearly closer to the current distribution of the Africanized honeybees (although, as discussed below, there are some important differences) than any of the other six subspecies. Both A. m. jementica and A. m. monticola show somewhat similar projections to those from A. m. scutellata, but much more restricted in some regions, especially in the US. All other subspecies show very different and unique potential distributions.

The Mantel test comparing the similarity of potential distributions between continents among subspecies (Table 1) revealed a significant correlation $(r=0.55, P=0.015$ with 5000 permutations), in such a way that subspecies with very distinct original distributions in Africa tend also to have dissimilar projected distributions in New World.

\section{Discussion}

A comparative analysis of projections from models based on different ancestral niche characteristics can provide additional information regarding niche dynamics of Africanized honeybees. Detailed patterns of abundance of Africanized honeybees are only fragmentary known and there is only a coarse expectation of its distribution, thus preventing us from adopting a more quantitative explicit comparison. It is possible, however, to rely both on the knowledge of distributional limits and suitable habitats for the subspecies in Americas, which are scattered throughout the literature, and on the information about the bees dispersion since the original introduction in Brazil, presuming that the highest rates of expansion occurred in the most suitable habitats (see Mistro et al. 2005 for an range expansion map). This way, it was possible to understand matches between current and projected distributions, although not precisely.

The models based on data from the distributions of all seven subspecies suggest that the current distribution of Africanized honeybees in New World reflects, to a great extent, niche-specific characteristics of the subspecies from which they were originated. Indeed, the potential distribution shown in these maps apparently make some sense given the knowledge of the subspecies' ecological features (Ruttner 1988), as discussed below, and provide 


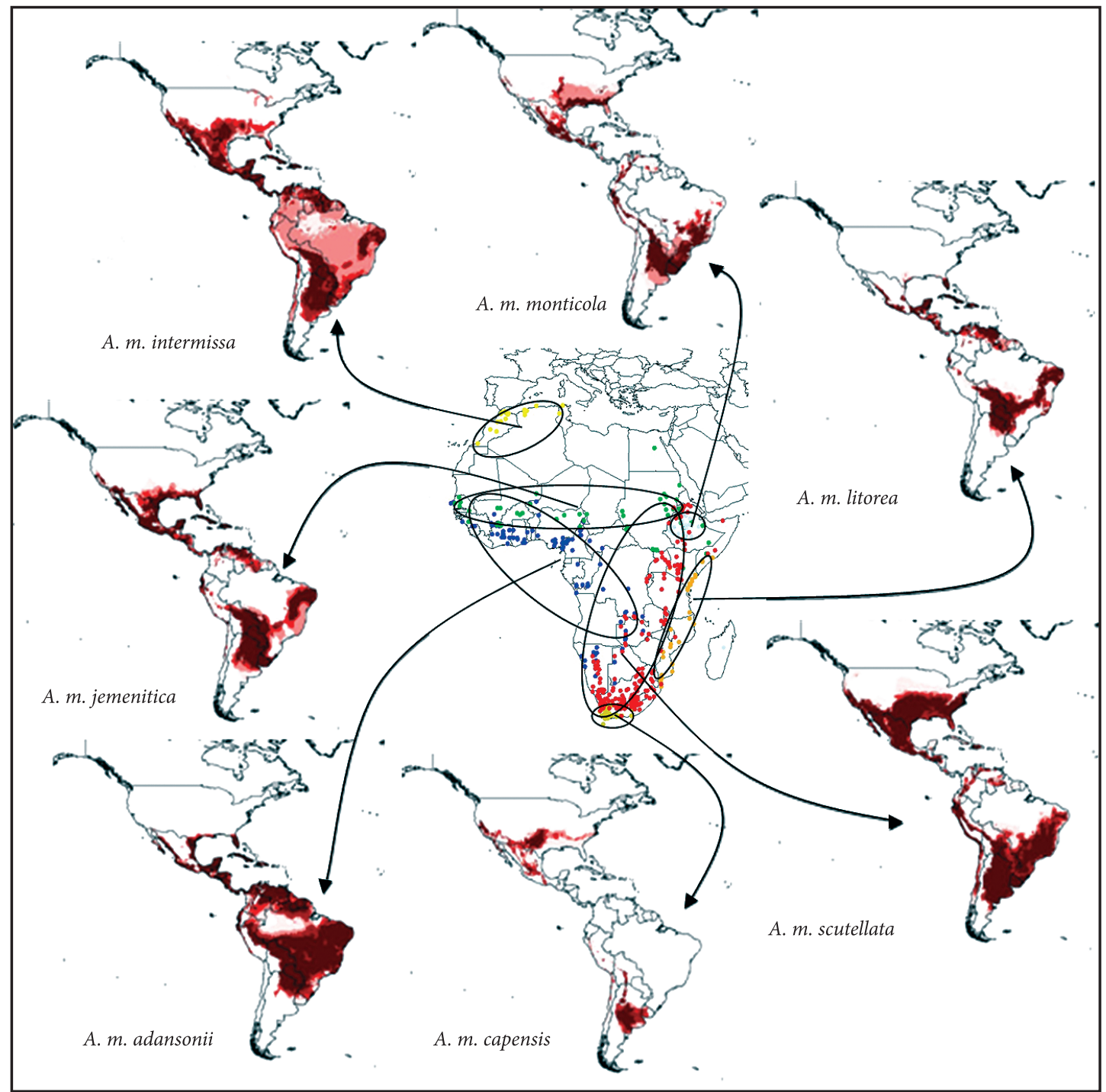

Figure 2. Projections of predictive models based on data of the distribution in Africa of all seven studied subspecies. The color scale represents the number of models predicting the occurrence in the same place, following the same scale as Figure 1.

support to the identity of $A$. m. scutellata as the ancestor subspecies of the Africanized honey bees currently found in New World.

The subspecies generally assumed to be introduced in Brazil in 1956 is A. m. scutellata (Smith et al. 1989). The projection of models generated from the original distribution of $A . m$. scutellata in Africa quite closely match what is known about the area currently occupied by the Africanized honeybees in New World. A. m. jemenitica results are very similar to A. m. scutellata's except for the smaller projected distribution. Along with A. m. scutellata, this tropical adapted subspecies come from warm and dry regions in Africa. Its more restricted distribution could be explained by a greater dependency of a dry climate. The other similar (but even more restricted) prediction comes from A. m. monticola data. This subspecies actually originates from an area that is almost entirely enclosed by A. m. scutellata's distribution, although it is utterly confined to higher altitudes. Its dependence of a cooler montane climate, thus, is reflected in a very constrained potential distribution. Next, let us consider A. m. adansonii's potential distribution: it is also a tropical adapted subspecies, but the models suggest a much more limited distribution both north and south of the continent and, on the other hand, they strongly suggest the occupation of the rainforest areas in the Amazonian region. This is also a very accurate prediction, in terms of A. $m$. adansonii original distribution which in part come from humid rainforest regions in Africa. Finally, A. m. litorea occupies a very restricted coastal distribution in Africa and produced a relatively restricted and fragmented range in the New World.

Furthermore, there are also two subtropical subspecies analyzed here, from which only poor predictions of current distribution of Africanized honeybees can be derived. The 


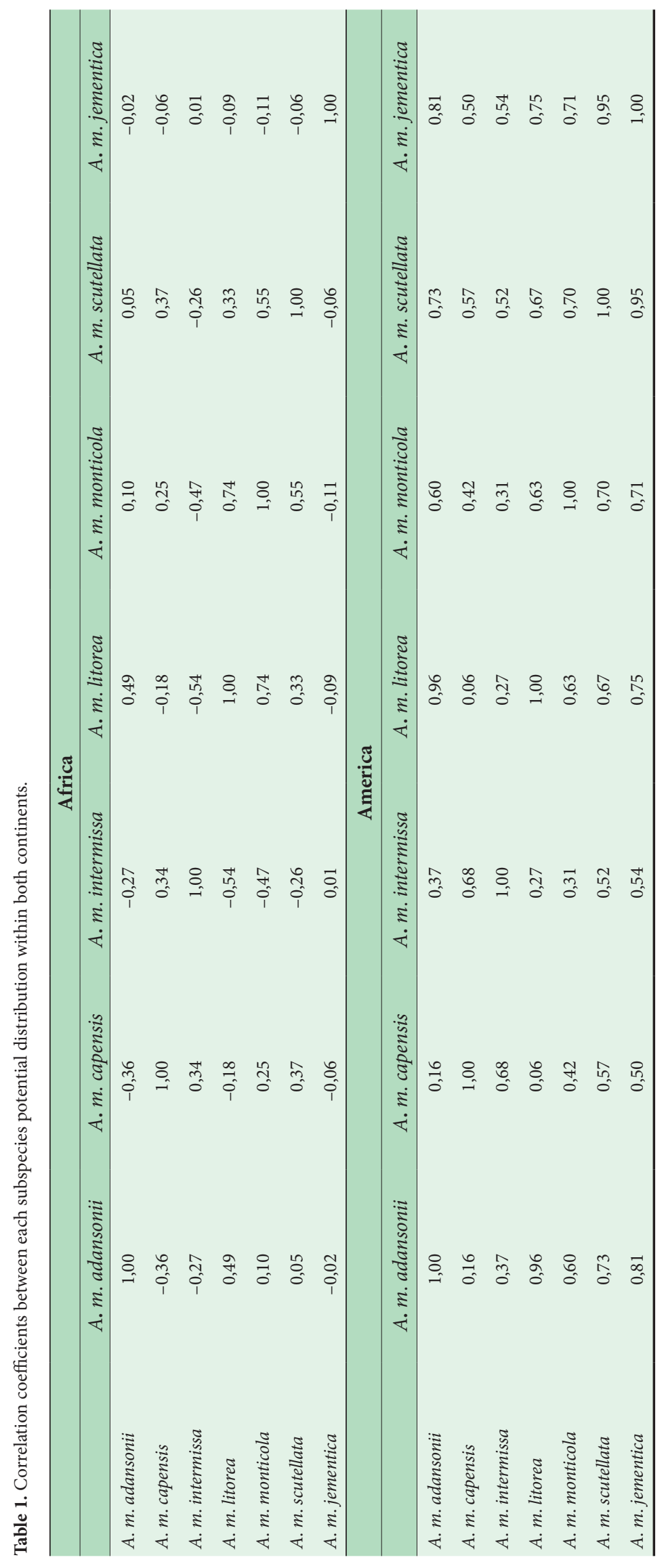


first is A.m. capensis, adapted to a local temperate climate in African and thus with a very restricted modeled distribution in the New World. Second, A. m. intermissa, a subspecies that is adapted to a climate somehow intermediate between tropical and temperate, thus have a distribution restricted in some regions, with large areas predicted by only few models (like in the Amazonian region), suggesting poorly adequacy to Neotropical environment.

It is important to stress that the projected distribution does not take into account the absence of factors that could diminish the fundamental niche in the original distribution, such as the presence of competitors (see Araújo \& Guisan 2006). So, projections from niche-based models can underestimate the area occupied by an invader in a competition-free invaded environment, and the real distribution projected from any of those subspecies of honeybees could be actually much larger than is proposed here.

Our evaluation of the models thus suggests that the best prediction of Africanized honeybees distribution in New World was generated using A. m. scutellata's data, which was indeed the ancestral subspecies of Africanized honeybees (Schneider et al. 2004). This confirms that current pattern of Africanized distribution is in a great extent due to its niche in Africa. A conspicuous feature of the projected A. $m$. scutellata distribution is the absence of models predicting the occurrence in most of the Amazonian region. Despite that the colonization history suggests the dispersion through this region, there is a lack of studies discussing if they are truly established in this area. Furthermore, the occurrences of A. m. scutellata, predominatly dwelling in thorn woodland and grass savannah in Africa's rain forests are of very low density (Michener 1975), thus supporting this results. In addition, the models also show a large suitable area in southern Argentina, not currently occupied, but this probably reflects the already observed incursions of the bees in this region during hot months (Kerr et al. 1982). Besides, it has been suggested that climate itself does not directly impose a limit to the bees' distribution in this region, and this would be determined by food and nesting site availability (Dietz et al. 1985).

There is, however, on important exception in the match of A. m. scutellata predicted distribution and the known distribution of the africanized bees: the large area in the eastern US predicted as suitable, that has not been colonized, though it has also been predicted in another study (Villa et al. 1993). If the models produced here are correct, then the absence of the invaders in this region could be explained by two reasons: (i) the area is not colonized yet, but it will be in the next years; (ii) a non-climatic factor is precluding the occupation, since our model suggests that climate itself is suitable. It does not seem to be any kind of geographical barrier that could be hampering the expansion of the Africanized bees. Although it could be possible that control performed by the beekeepers of this region is delaying the expansion, this cannot explain why the eastward invasion is much slower (http://www.ars.usda.gov/Research/docs. htm? docid=11059\&page=6, last updated in March 2011). It has also been suggested that the presence of the bee mite Varroa destructor could act this way, especially in those areas with high rainfall (Villa et al. 2002). Furthermore, it is difficult to predict how long the bee's migration will be prevented: even though eastern US is not yet occupied after 22 years since the first AHB record in the country, the expansion has not stopped (http://www.ars.usda.gov/ Research/docs.htm?docid=11059\&page=6).

A further quantitative evaluated this overall pattern was provided by the significant correlation between the similarity matrices of the distribution models for each subspecies in Africa and in America. Thus, despite differences between A. m. scutellata and Africanized honeybees and the discussion around the morphological clines in New World (which can be explained by racial admixture or adaptation, see Diniz-Filho \& Malaspina (1995), the analyses performed here support importance of niche conservatism processes (Wiens \& Graham 2005) in driving geographical distributions. Most importantly, niche conservatism is a critical assumption when modeling responses of biodiversity and distributional shifts in response to global climate changes (Diniz-Filho \& Bini 2008). So, our results reinforce the need to better understand these patterns and processes to make accurate predictions and allow optimal solutions to the problems caused by these changes.

\section{Acknowledgements}

We are indebted to J. A. F. Diniz-Filho, whom advising was vital for this work. We thank D. Stockewell for a helpful discussion in GARP mailing list. P. De Marco Jr., L. M. Bini, R. Angelini and D. Brandão gave valuable suggestions on earlier versions of this manuscript. Finally, we would like to thank an anonymous referee who made appreciated comments after submission.

\section{References}

Anderson RP, Lew D \& Peterson AT, 2003. Evaluating predictive models of species' distributions: criteria for selecting optimal models. Ecological Modeling, 162:211-232. http://dx.doi. org/10.1016/S0304-3800(02)00349-6

Araújo MB \& Guisan A, 2006. Five (or so) challenges for species distribution modeling. Journal of Biogeography, 33:16771688. http://dx.doi.org/10.1111/j.1365-2699.2006.01584.x

Araújo VP, 1971. The central African bee in south America. Bee World, 52:116-121.

Dietz A, Krell R \& Eischen FA, 1985. Preliminary Investigation on the Distribution of Africanized Honey Bees in Argentina. Apidologie, 16:99-107. http://dx.doi.org/10.1051/ apido:19850201

Diniz-Filho JAF \& Malaspina O, 1995. Evolution and population structure of Africanized honey bees in Brazil: Evidence from spatial analysis of morphometric data. Evolution, 49:1172-1179. http://dx.doi.org/10.2307/2410442 
Diniz-Filho JAF \& Bini LM, 2008. Macroecology, global change and the shadow of forgotten ancestors. Global Ecology and Biogeography, 17:11-17.

Diniz-Filho JAF et al., 2000. Spatial analysis of morphological variation in African honeybees (Apis mellifera L.) on a continental scale. Apidologie, 31:191-204. http://dx.doi. org/10.1051/apido:2000116

Elith J et al., 2006. Novel methods improve prediction of species' distributions from occurrence data. Ecography, 29:129-151. http://dx.doi.org/10.1111/j.2006.0906-7590.04596.x

Genovesi P, 2005. Eradications of invasive alien species in Europe: a review. Biological Invasions, 7:127-133. http:// dx.doi.org/10.1007/s10530-004-9642-9

Harrison JF et al. 2006. Environmental physiology of the invasion of the Americas by Africanized Honeybees. Integrative and Comparative Biology, 46:1110-1122. PMid:21672812. http:// dx.doi.org/10.1093/icb/icl046

Hepburn HR \& Radloff SE, 1998. Honeybees of Africa. Berlin: Springer.

Kerr WE, Delrio SD \& Barrionuevo MD, 1982. The Southern Limits of the Distribution of the Africanized Honey Bee in South-America. American Bee Journal, 122:196-198.

Lodge DM \& Shrader-Frechette K, 2003. Nonindigenous species: Ecological explanation, environmental ethics, and public policy. Conservation Biology, 17:31-37. http://dx.doi. org/10.1046/j.1523-1739.2003.02366.x

Manly BFJ, 1997. Randomization, Bootstrap and Monte Carlo Methods in Biology. London: Chapman \& Hall.

Michener CD, 1975. Brazilian Bee Problem. Annual Review of Entomology, 20:399-416. PMid:1090242. http://dx.doi. org/10.1146/annurev.en.20.010175.002151

Mistro DC, Rodrigues LAD \& Ferreira Junior WC, 2005. The Africanized honey bee dispersal: a mathematical zoom. Bulletin of Mathematical Biology, 67:281-312. PMid:15710182. http://dx.doi.org/10.1016/j.bulm.2004.07.006

Myers JH et al., 2000. Eradication revisited: dealing with exotic species. Trends in Ecology \& Evolution, 15:316-320. http:// dx.doi.org/10.1016/S0169-5347(00)01914-5

Peterson AT, 2003. Predicting the geography of species' invasions via ecological niche modeling. Quarterly Review of Biology, 78:419-433. PMid:14737826. http://dx.doi. org/10.1086/378926

Peterson AT \& Robins CR, 2003. Using EcologicalNiche Modeling to Predict Barred Owl Invasions with Implications for Spotted Owl Conservation. Conservation Biology, 17:1161-1165. http://dx.doi. org/10.1046/j.1523-1739.2003.02206.x

Peterson AT \& Vieglais DA, 2001. Predicting species invasions using ecological niche modeling: New approaches from bioinformatics attack a pressing problem. Bioscience, 51:363-371. http://dx.doi. org/10.1641/0006-3568(2001)051[0363:PSIUEN]2.0.CO;2

Peterson AT, Papes M \& Eaton M, 2007. Transferability and model evaluation in ecological niche modeling: a comparison of GARP and Maxent. Ecography, 30:550-560.

Ruttner F, 1988. Biogeography and taxonomy of honeybees. Berlim: Spinger.

Schneider SS, Hoffman GD \& Smith DR, 2004. The African honey bee: Factors contributing to a successful biological invasion. Annual Review of Entomology, 49:51-376.

Smith DR, Taylor OR \& Brown WM, 1989. Neotropical Africanized honey bees have African mitochondrial DNA. Nature, 339:213-215. PMid:2566123. http://dx.doi. org $/ 10.1038 / 339213 \mathrm{a} 0$

Stockman AK, Beamer DA \& Bond JE, 2006. Predicting the distribution of non-vagile taxa: a response to McNyset and Blackburn (2006) and re-evaluation of Stockman et al (2006). Diversity and Distributions, 12:787-792. http:// dx.doi.org/10.1111/j.1472-4642.2006.00296.x

Stockwell DRB \& Peterson AT, 2002. Effects of sample size on accuracy of species distribution models. Ecological Modeling, 148:1-13. http://dx.doi.org/10.1016/ S0304-3800(01)00388-X

Taylor OR, 1977. Past and Possible Future Spread of Africanized Honeybees in Americas. Bee World, 58:19-30.

Villa JD, Rinderer TE \& Collins AM, 1993. Overwintering of Africanized, European, and Hybrid Honey-Bees (Hymenoptera, Apidae) in the Andes of Venezuela. Environmental Entomology, 22:183-189.

Villa JD, Rinderer TE \& Stelzer JA, 2002. Answers to the puzzling distribution of Africanized bees in the United States - "Why are those bees not moving east of Texas?". American Bee Journal, 142:480-483.

Wiens JJ \& Graham CH, 2005. Niche conservatism: Integrating evolution, ecology, and Conservation Biology. Annual Review of Ecology, Evolution and Systematics, 36:519-539. http://dx.doi.org/10.1146/annurev.ecolsys.36.102803.095431 